\section{Local complement activation in aqueous humor in patients with age-related macular degeneration}

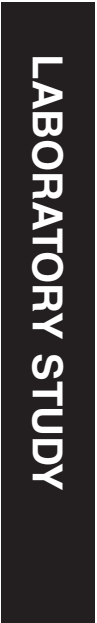

${ }^{1}$ Department of Ophthalmology, University Hospital of Cologne, Cologne, Germany

${ }^{2}$ Laboratory for Experimental Immunology of the Eye, Department of Ophthalmology, University Hospital of Cologne,

Cologne, Germany

${ }^{3}$ Institute of Immunology, University of Heidelberg, Heidelberg, Germany

Correspondence:

$S$ Fauser, Department of Ophthalmology, University Hospital of Cologne, Kerpener Str. 62, 50924 Cologne, Germany Tel: +49 (0)221 4784105 ; Fax: +49 (0)221 4785922. E-mail: sascha.fauser@ gmail.com

Received: 30 August 2016 Accepted in revised form: 18 December 2016; Published online: 27 January 2017

\begin{abstract}
Purpose To investigate complement activation in aqueous humor and in plasma of patients with neovascular age-related macular degeneration (nAMD).

Patients and methods Aqueous humor and EDTA-plasma of $31 \mathrm{nAMD}$ patients and 30 age-matched controls was collected. The levels of the complement factor 3 (C3), the regulators factor $\mathrm{H}(\mathrm{FH})$, and factor $\mathrm{I}(\mathrm{FI})$, and of the complement activation products $\mathrm{Ba}$, $\mathrm{C} 3 \mathrm{a}$, and the terminal complement complex (sC5b-9) were measured. Associations between complement levels and phenotype were determined using Mann-Whitney $U$-test. Results In plasma, no significant differences were found between the nAMD group and the control group. In aqueous humor, significantly increased levels of $\mathrm{Ba}(P=0.002)$, and $\mathrm{C} 3 \mathrm{a}(P=0.002)$ indicate local complement activation in nAMD patients and a trend for a concomitant upregulation of the complement regulators FH $(P=0.02)$ and FI $(P=0.04)$.

Conclusions Our findings provide strong evidence for a local complement dysregulation in nAMD patients. Eye (2017) 31, 810-813; doi:10.1038/eye.2016.328; published online 27 January 2017
\end{abstract}

\section{Introduction}

Age-related macular degeneration (AMD) is a major cause of blindness in the elderly population. In the early stages, deposits of cellular debris and inflammatory material accumulate between retinal pigment epithelium and Bruch's membrane. Late AMD is characterized by the development of either geographic atrophy or neovascular AMD (nAMD). A dysregulation of the alternative pathway of the complement
T Schick1', M Steinhauer'1, A Aslanidis², L Altay', M Karlstetter ${ }^{2}$, T Langmann², M Kirschfink ${ }^{3}$ and $\mathrm{S}$ Fauser $^{1}$ cascade has been postulated to be the key to the pathogenesis of AMD. ${ }^{1-4}$ Various complement proteins, their activation products, and regulators have been identified in retinal deposits of AMD patients. Several genes that are associated with AMD encode for proteins of the complement system, including the components component 3 (C3), component $2(\mathrm{C} 2)$, and factor $\mathrm{B}(\mathrm{FB})$, as well as the regulators factor $\mathrm{H}(\mathrm{FH})$ and factor I (FI). ${ }^{1,5-12}$

Although AMD disease manifestation is localized in the eye, a slight systemic elevation of complement components and activation products in AMD patients were found for $\mathrm{FB}$ and factor D as well as for 3a, C5a, C3d, and Ba, respectively. ${ }^{13,14}$ However, little is known about the extent and relationship between systemic and local complement dysregulation in AMD. In this study, we analyzed various complement proteins, their activation products and regulators in aqueous humor and in EDTAplasma of patients with and without nAMD.

\section{Methods}

\section{Study population}

In this prospective study, 61 participants (31 nAMD patients, 30 age-matched controls) from the Department of Ophthalmology, University Hospital of Cologne were included. The study was performed in accordance with the tenets of the Declaration of Helsinki and the Medical Research Involving Human Subjects Act (WMO) and was approved by the local ethics committee of the University Hospital in Cologne. Written informed consent was obtained from all participants.

Patient staging was performed by grading of retinal images including stereo fundus photographs in controls and fundus photographs, fluorescein angiograms, and spectral domain optical coherence tomograms in 
nAMD patients. Controls had no drusen in both eyes, nAMD was classified by active choroidal

neovascularisation secondary to AMD in the study eye at the time point of collection of samples.

\section{Inclusion and exclusion criteria}

Included were patients with nAMD undergoing IVI with anti-VEGF agents (bevazizumab, ranibizumab, or aflibercept) as well as controls undergoing cataract surgery. Exclusion criteria were any previous ophthalmic surgery during the last 6 months. In the nAMD group, IVI with anti-VEGF agents (bevazizumab, ranibizumab, or aflibercept) were allowed to be injected more than 4 weeks ago and therefore were not an exclusion criterion. Additional exclusion criteria were ocular malignoma, diseases resulting in inflammation or hemorrhage in the study eye and any systemic diseases potentially inducing the complement system such as diabetes, autoimmune diseases, cancer, or infectious diseases.

\section{Collection of samples}

Undiluted samples of aqueous humor were acquired before any other surgical manipulation of the cataract operation and before IVI. An aliquot of $0.1 \mathrm{ml}$ of aqueous humor was collected via limbal paracentesis using a 30 -gauge needle connected to an insulin syringe. Care was taken not to contaminate the sample with blood. Samples were transferred to sterile polypropylene tubes immediately after collection and stored at $-80{ }^{\circ} \mathrm{C}$ until analysis was performed.

\section{Measurements of complement levels}

$\mathrm{C} 3, \mathrm{FH},{ }^{15} \mathrm{FI},{ }^{16}$ and $\mathrm{sC} 5 \mathrm{~b}-9^{17}$ were measured by ELISA as previously described. C3a (Progen, Heidelberg, Germany) and Ba (Quidel, San Diego, CA, USA) were measured by ELISA following the manufacturer's protocols. All assays were adapted for analysis in aqueous humor.

\section{Statistical analysis}

All calculations were performed using SPSS software version 22.0 (IBM Software and Systems, Armonk, NY, USA). Mann-Whitney $U$-test (two-sided) was used to compare complement levels in the nAMD group and the control group. Correlations in nAMD cases between number of IVIs and complement levels and between local and systemic complement levels were performed using Spearman correlation (two-sided). Bonferroni correction was performed due to multiple testing and $P$-values $<0.0045$ were considered statistically significant. As this is a pilot study and no boundary values for local complement values exist, power calculations could not be performed previously.

\section{Results}

In the study, 30 controls and 31 patients with nAMD were included. Age did not differ significantly between both groups $(P=0.09$; controls: mean \pm SD $73.3 \pm 5.9$ years $v s$ AMD patients $75.5 \pm 4.8$ years). In the control group, 21 were male, the $\mathrm{AAMD}$ group comprised 11 male participants. Mean number of previous IVIs in the nAMD group was 5.4 (range 0-14 IVIs). Complement protein concentrations did not correlate with the number of previous IVIs (Table 1). Concentrations for all parameters for nAMD patients and controls are summarized in Table 2.

In plasma, none of the tested complement parameters showed a significant difference between nAMD patients and controls (Table 2). In aqueous humor, nAMD patients had significantly higher levels of complement activation markers $\mathrm{Ba}$ and $\mathrm{C} 3 \mathrm{a}$, but also a trend for an upregulation of the regulatory proteins FH and FI (Table 2). Local and systemic complement levels showed slight positive correlation for Ba and C3 (Table 3).

\section{Discussion}

Increased complement activation has been suggested to be one of the main pathomechanisms in AMD. This hypothesis is supported by large genetic association studies. ${ }^{7}$ All relevant complement genes associated with activation and regulation of the complement activation pathways are expressed locally in the human RPEchoroid complex. ${ }^{18}$

In this study, we analyzed complement C3, activation markers and regulatory proteins in aqueous humor and in

Table 1 Influence of number of IVIs in the group of patients with neovascular age-related macular degeneration on complement levels

\begin{tabular}{ll}
\hline Parameter & Number of IVIs (Spearman correlation) \\
\hline Plasma & \\
SC $5 \mathrm{~b}-9(\mathrm{ng} / \mathrm{ml})$ & $R=0.05, P=0.83$ \\
Ba $(\mathrm{n} / \mathrm{ml})$ & $R=0.09, P=0.69$ \\
FH $(\mu \mathrm{g} / \mathrm{ml})$ & $R=-0.24, P=0.27$ \\
FI $(\mu \mathrm{g} / \mathrm{ml})$ & $R=-0.38, P=0.08$ \\
C3 $(\mu \mathrm{g} / \mathrm{ml})$ & $R=-0.26, P=0.22$ \\
C3a $(\mathrm{ng} / \mathrm{ml})$ & $R=0.22, P=0.33$ \\
& \\
Aqueous humor & $R=-0.08, P=0.72$ \\
Ba $(\mathrm{ng} / \mathrm{ml})$ & $R=-0.09, P=0.71$ \\
FH $(\mu \mathrm{g} / \mathrm{ml})$ & $R=-0.32, P=0.17$ \\
FI $(\mu \mathrm{g} / \mathrm{ml})$ & $R=-0.37, P=0.11$ \\
C3 $(\mu \mathrm{g} / \mathrm{ml})$ & $R=-0.09, P=0.68$ \\
C3a $(\mathrm{ng} / \mathrm{ml})$ & \\
\hline
\end{tabular}


Table 2 Median complement factor levels in plasma and aqueous humor in NAMD patients and controls

\begin{tabular}{|c|c|c|c|}
\hline \multirow[t]{2}{*}{ Parameter } & \multicolumn{2}{|c|}{ Median (1st-3rd quartile) } & \multirow[t]{2}{*}{ P-value } \\
\hline & Control & $n A M D$ & \\
\hline \multicolumn{4}{|l|}{ Plasma } \\
\hline SC5b-9 (ng/ml) & 151 (113-199) & $175(121-224)$ & 0.17 \\
\hline $\mathrm{Ba}(\mathrm{n} / \mathrm{ml})$ & $710(535-851)$ & 738 (645-906) & 0.20 \\
\hline $\mathrm{FH}(\mu \mathrm{g} / \mathrm{ml})$ & $289(252-368)$ & $298(270-367)$ & 0.58 \\
\hline FI $(\mu \mathrm{g} / \mathrm{ml})$ & $27.5(23-35)$ & $26.5(23-31)$ & 0.42 \\
\hline $\mathrm{C} 3(\mu \mathrm{g} / \mathrm{ml})$ & $985(720-1170)$ & $895(655-1027)$ & 0.11 \\
\hline $\mathrm{C} 3 \mathrm{a}(\mathrm{ng} / \mathrm{ml})$ & $292(239-410)$ & $298(218-422)$ & 0.89 \\
\hline \multicolumn{4}{|l|}{ Aqueous humor } \\
\hline $\mathrm{Ba}(\mathrm{ng} / \mathrm{ml})$ & $11.5(7.0-21.5)$ & $22.8(16.2-28.5)$ & $0.002^{*}$ \\
\hline $\mathrm{FH}(\mu \mathrm{g} / \mathrm{ml})$ & $0.13(0.09-0.21)$ & $0.16(0.13-0.37)$ & 0.02 \\
\hline FI $(\mu \mathrm{g} / \mathrm{ml})$ & $0.11(0.08-0.20)$ & $0.17(0.11-0.28)$ & 0.04 \\
\hline C3 ( $\mu \mathrm{g} / \mathrm{ml})$ & $0.72(0.29-1.33)$ & $0.78(0.47-2.22)$ & 0.25 \\
\hline C3a (ng/ml) & $21.0(13.8-26.0)$ & $33.0(24.3-37.5)$ & $0.002^{*}$ \\
\hline
\end{tabular}

Abbreviation: nAMD, neovascular AMD. Mann-Whitney $U$-test, *statistically significant (after Bonferroni correction, if $P<0.0045$ ).

Table 3 Spearman correlation of plasma and aqueous humor levels per parameter

\begin{tabular}{lcl}
\hline Parameter & $R$ & $P$-value \\
\hline Ba & 0.53 & 0.00003 \\
FH & 0.34 & 0.03 \\
FI & 0.43 & 0.006 \\
C3 & 0.44 & 0.001 \\
C3a & 0.25 & 0.10 \\
\hline
\end{tabular}

plasma of patients with nAMD and healthy controls. Although plasma concentrations of complement proteins showed no significant difference between both groups, activation products $\mathrm{C} 3 \mathrm{a}$ and $\mathrm{Ba}$ were significantly elevated in aqueous humor of nAMD patients. In addition, there was a trend for elevated regulators $\mathrm{FH}$ and FI in aqueous humor in nAMD.

Thus, complement activation was significantly increased despite a trend for an upregulation of complement inhibitors. Therefore, inhibitors could not compensate for an increased yet unidentified stimulus for complement activation.

Although systemic complement activation in plasma was slightly increased in AMD patients compared with controls, the difference was statistically not significant.

This was in clear contrast to the very pronounced increase in complement activation in aqueous humor.

In plasma, other studies also found increased plasma complement levels in patients with AMD. ${ }^{13,14}$ The differences were statistically significant due to slightly higher median values in a large number of samples with a big overlap in the range of values between both groups.
This is not relevant on the individual level because there is a large variation in systemic complement levels. In addition, various factors and common diseases such as diabetes have influence on systemic complement activation and impede the interpretation.

Between local and systemic complement levels, we could find slight correlations for Ba and C3. Therefore, for some components there might be a low influence on systemic complement levels due to local complement activation in AMD patients.

Overall, this data supports the notion that there is a significant dysregulation of the complement cascade in AMD. We could demonstrate that this is essentially a local event in the eye more than in the systemic circulation.

Our study comprised a relatively small number of samples and reference values of the measured intraocular complement levels do not exist yet which is mainly due to the limited access to aqueous humor samples. Number of injections of anti-VEGF agents $>4$ weeks before collection of samples did not correlate with complement levels but an influence of IVIs cannot be ruled out. Hence, larger cohorts of therapy-naïve patients and controls should be analyzed in further studies. Only data on patients with nAMD but not on dry AMD were available for this study. Based on measurements of plasma samples with small differences in complement activation between both wet and dry AMD, and controls it is likely that ocular complement activation is also increased in dry AMD. ${ }^{19}$

In conclusion, our study clearly demonstrates increased complement activation in aqueous humor of nAMD patients supporting the hypothesis of a local dysregulation of the complement system in AMD.

\section{Summary}

What was known before

- In age-related macular degeneration (AMD) a dysregulation of the alternative pathway of the complement cascade has been postulated to be the key to the pathogenesis. A slight systemic elevation of complement components and activation products were found in AMD patients. However, little is known about the extent of a local complement dysregulation.

What this study adds

- In aqueous humor, significantly increased levels of activation products indicate local complement activation in $\mathrm{nAMD}$ patients despite a concomitant upregulation of complement regulators. A local overactivation of the complement system seems to take place in AMD.

\section{Conflict of interest}

The authors declare no conflict of interest. 


\section{References}

1 Gold B, Merriam JE, Zernant J, Hancox LS, Taiber AJ, Gehrs $\mathrm{K}$ et al. Variation in factor B (BF) and complement component 2 (C2) genes is associated with age-related macular degeneration. Nat Genet 2006; 38(4): 458-462.

2 Hageman GS, Luthert PJ, Victor Chong NH, Johnson LV, Anderson DH, Mullins RF. An integrated hypothesis that considers drusen as biomarkers of immune-mediated processes at the RPE-Bruch's membrane interface in aging and age-related macular degeneration. Prog Retin Eye Res 2001; 20(6): 705-732.

3 Johnson PT, Betts KE, Radeke MJ, Hageman GS, Anderson DH, Johnson LV. Individuals homozygous for the age-related macular degeneration risk-conferring variant of complement factor $\mathrm{H}$ have elevated levels of CRP in the choroid. Proc Natl Acad Sci USA 2006; 103(46): 17456-17461.

4 Nozaki M, Raisler BJ, Sakurai E, Sarma JV, Barnum SR, Lambris JD et al. Drusen complement components C3a and C5a promote choroidal neovascularization. Proc Natl Acad Sci USA 2006; 103(7): 2328-2333.

5 Edwards AO, Ritter R 3rd, Abel KJ, Manning A, Panhuysen C, Farrer LA. Complement factor $\mathrm{H}$ polymorphism and agerelated macular degeneration. Science 2005; 308(5720): 421-424.

6 Fritsche LG, Chen W, Schu M, Yaspan BL, Yu Y, Thorleifsson G et al. Seven new loci associated with age-related macular degeneration. Nat Genet 2013; 454: 433-439 439e431-432.

7 Fritsche LG, Igl W, Bailey JN, Grassmann F, Sengupta S, Bragg-Gresham JL et al. A large genome-wide association study of age-related macular degeneration highlights contributions of rare and common variants. Nat Genet 2016; 48(2): 134-143.

8 Haines JL, Hauser MA, Schmidt S, Scott WK, Olson LM, Gallins $\mathrm{P}$ et al. Complement factor $\mathrm{H}$ variant increases the risk of age-related macular degeneration. Science 2005; 308(5720): 419-421.

9 Klein RJ, Zeiss C, Chew EY, Tsai JY, Sackler RS, Haynes C et al. Complement factor $\mathrm{H}$ polymorphism in age-related macular degeneration. Science 2005; 308(5720): 385-389.
10 Maller JB, Fagerness JA, Reynolds RC, Neale BM, Daly MJ, Seddon JM. Variation in complement factor 3 is associated with risk of age-related macular degeneration. Nat Genet 2007; 39(10): 1200-1201.

11 van de Ven JP, Nilsson SC, Tan PL, Buitendijk GH, Ristau T, Mohlin FC et al. A functional variant in the CFI gene confers a high risk of age-related macular degeneration. Nat Genet 2013; 45(7): 813-817.

12 Yates JR, Sepp T, Matharu BK, Khan JC, Thurlby DA, Shahid H et al. Complement $\mathrm{C} 3$ variant and the risk of age-related macular degeneration. N Engl J Med 2007; 357(6): 553-561.

13 Scholl HP, Charbel Issa P, Walier M, Janzer S, Pollok-Kopp B, Borncke $\mathrm{F}$ et al. Systemic complement activation in age-related macular degeneration. PLoS One 2008; 3(7): e2593.

14 Ristau T, Paun C, Ersoy L, Hahn M, Lechanteur Y, Hoyng C et al. Impact of the common genetic associations of agerelated macular degeneration upon systemic complement component C3d levels. PLoS One 2014; 9(3): e93459.

15 Licht C, Weyersberg A, Heinen S, Stapenhorst L, Devenge J, Beck B et al. Successful plasma therapy for atypical hemolytic uremic syndrome caused by factor $\mathrm{H}$ deficiency owing to a novel mutation in the complement cofactor protein domain 15. Am J Kidney Dis 2005; 45(2): 415-421.

16 Grumach AS, Leitao MF, Arruk VG, Kirschfink M, CondinoNeto A. Recurrent infections in partial complement factor I deficiency: evaluation of three generations of a Brazilian family. Clin Exp Immunol 2006; 143(2): 297-304.

17 Kotnik V, Luznik-Bufon T, Schneider PM, Kirschfink M. Molecular, genetic, and functional analysis of homozygous C8 beta-chain deficiency in two siblings. Immunopharmacology 1997; 38(1-2): 215-221.

18 Anderson DH, Radeke MJ, Gallo NB, Chapin EA, Johnson PT, Curletti CR et al. The pivotal role of the complement system in aging and age-related macular degeneration: hypothesis re-visited. Prog Retin Eye Res 2010; 29(2): 95-112.

19 Reynolds R, Hartnett ME, Atkinson JP, Giclas PC, Rosner B, Seddon JM. Plasma complement components and activation fragments: associations with age-related macular degeneration genotypes and phenotypes. Invest Ophthalmol Vis Sci 2009; 50(12): 5818-5827. 